\title{
ENSINO MÉDIO INOVADOR: RESSIGNIFICAÇÕES DE EDUCAÇÃO DE QUALIDADE EM CONTEXTOS LOCAIS
}

JEAN MAC COLE TAVARES SANTOS

\section{RESUMO}

Neste artigo, apresentamos uma pesquisa realizada com docentes de duas escolas públicas de ensino médio do estado do Ceará sobre os sentidos atribuídos à qualidade na educação a partir das ações do Programa Ensino Médio Inovador. Com base na concepção de ciclo de políticas de Ball e Bowe (1998), entendemos que as políticas educacionais são produções de significações curriculares desenvolvidas em múltiplos contextos. Rompendo com a polarização dicotômica entre política e prática, buscamos superar a compreensão da escola como local somente de resistência ou de implementação da política, já que os documentos do Ministério da Educação, mesmo que aceitos pela escola, são reelaborados, traduzidos, ressignificados na cultura escolar. Assim, as ressignificações efetivadas nas escolas se diferenciam de acordo com o grau de reconhecimento, com a credibilidade da instituição e de sua relação com a comunidade escolar, com os órgãos diretivos e com sua própria história.

PALAVRAS-CHAVE QUALIDADE DO ENSINO • ENSINO MÉDIO • PROGRAMA ENSINO MÉDIO INOVADOR - PROEMI • POLÍTICAS PÚBLICAS EM EDUCAÇÃO. 


\section{RESUMEN}

En este artículo presentamos una investigación realizada con docentes de dos escuelas públicas de educación media del estado de Ceará sobre los sentidos atribuidos a la calidad en educación a partir de las acciones del Programa Ensino Médio Inovador [Programa Educación Media Innovadora]. En base a la concepción del ciclo de politicas de Ball y Bowe (1998), entendemos que las políticas educacionales son producciones de significaciones curriculares desarrolladas en múltiples contextos. Rompiendo con la polarización dicotómica entre política y práctica, buscamos superar la comprensión de la escuela como sitio solamente de resistencia o de implementación de la política, ya que los documentos del Ministerio de Educación, aunque aceptados por la escuela, son reelaborados, traducidos, resignificados en la cultura escolar. Así, las resignificaciones efectuadas en las escuelas se diferencian de acuerdo con el grado de reconocimiento, la credibilidad de la institución y su relación con la comunidad escolar, con los órganos directivos y con su propia historia.

PALABRAS CLAVE CALIDAD DE LA ENSEÑANZA • EDUCACIÓN MEDIA • PROGRAMA ENSINO MÉDIO INOVADOR - PROEMI • POLÍTICAS PÚBLICAS EN EDUCACIÓN.

\section{ABSTRACT}

In this article, we present a survey carried out with teachers from two secondary public school in the State ofCearáabout the meanings assigned to quality education grounded in the actions of the Programa Ensino Médio Inovador [Secondary School Innovative Program]. Based on the concept of policy cycle approach of Ball and Bowe (1998), we believe that educational policies are products of curricular meanings developed in multiple contexts. Breaking with the dichotomous polarization between policy and practice, we seek to overcome the understanding of school only as a place of policy resistance or implementation, since the documents of the Ministry of Education, even if accepted by the school, are rewritten, translated, and redefined in school culture. Thus, the redefinitions that occur in schools differ according to the degree of recognition, institution credibility and its relationship with the school community, directors and its own history.

KEYWORDS QUALITY EDUCATION - SECONDARY SCHOOL • PROGRAMA ENSINO MÉDIO INOVADOR - PROEMI - PUBLIC EDUCATION POLICIES. 
1 Pesquisa parcialmente financiada pelo Conselho Nacional de Desenvolvimento Científico e Tecnológico (CNPq) (bolsa de pós-doutorado e Edital Universa 2012/2015)
2 Como não é escopo deste artigo apresentar as diversas possibilidades de interpretar a "qualidade na educação", ação que desenvolvemos em outros textos, recomendamos estes estudos

que têm servido de apoio para a problematização e nosso entendimento

de qualidade na educação: Kulesza e Medeiros (2000); Candau (2002); Candau e Leite (2006); Gentili (2001): Enguita (2001); Lopes (1999, 2006); Demo (2001); Machado (2007); Lopes e Macedo (2011)

\section{INTRODUÇÃO}

Apresentamos, neste artigo, alguns resultados de uma pesquisa realizada com docentes de duas escolas públicas de ensino médio sobre os sentidos atribuídos à qualidade na educação a partir das atividades e dos projetos desenvolvidos nas instituições. ${ }^{1}$ Interessa-nos perceber como os docentes respondem às exigências e às expectativas dos projetos oficiais, aqueles que as escolas tomam como parâmetros para realizarem suas políticas educativas no que diz respeito ao polissêmico (ENGUITA, 2001), escorregadio (CANDAU, 2002) e flutuante (LOPES, 2012) conceito de qualidade na educação. ${ }^{2}$ Tomamos como base para o estudo as propostas do Ministério da Educação (MEC) para fortalecer essa modalidade de ensino, pois entendemos que tais contribuições, embora não sejam as únicas nem estejam isentas de críticas, são as que mais influenciaram o cotidiano escolar nos últimos 20 anos (SANTOS, 2007), estando sempre, em tese, voltadas para a melhoria da educação (KULESZA, MEDEIROS, 2000; CANDAU, 2002). Apesar de nossa investigação envolver, de forma geral, as atividades docentes, centramos nosso interesse 
nas ações desenvolvidas no Programa Ensino Médio Inovador (ProEMI). Nossa opção pelo ProEMI visa a manter uma referência em ações desenvolvidas nas escolas pelos docentes, sendo, assim, possível realizar uma reflexão mais balizada.

Utilizamos como operador teórico o ciclo de políticas de Ball e Bowe (1998), como apresentadas e discutidas a partir dos referenciais de Lopes (2006), Lopes e Macedo (2011), Ball e Mainardes (2011) e Mainardes (2006). Entendemos que as políticas educacionais são produções de significações curriculares desenvolvidas em múltiplos contextos. Queremos romper, portanto, com a polarização dicotômica entre política e prática, buscando superar a compreensão da escola como local somente de resistência ou de implementação da política. Dessa maneira, os sentidos de qualidade constituídos, em última instância, pelos documentos do MEC, mesmo que aceitos pela escola, são reelaborados, traduzidos, ressignificados $^{3}$ a partir do contexto (SANTOS; OLIVEIRA, 2013) e da cultura escolar (BALL, 1994a), tendo acepções diferentes em cada realidade, visto que são resultados de embates e disputas que envolvem múltiplos interesses: da escola, da docência, da comunidade, dos órgãos diretivos, entre outros. As ressignificações efetivadas nas escolas se diferenciam, portanto, de acordo com o grau de reconhecimento, com a credibilidade da instituição e de sua relação com a comunidade escolar, com os órgãos diretivos do estado e com sua própria história. O know-how da escola é, destarte, elemento definidor dos sentidos de qualidade.

As duas escolas pesquisadas, diferentes entre si em vários aspectos, como veremos mais adiante, foram escolhidas por terem em comum o fato de atuarem no ensino médio desde o processo inicial de expansão dessa modalidade de ensino. Isto é, conviveram com vários projetos do MEC, desde a Lei de Diretrizes e Bases da Educação (LDB), Lei n. 9.394/1996. Além disso, as duas aderiram ao ProEMI, condição mínima para a execução da pesquisa.

A pesquisa teve início com o estudo do Documento Norteador do ProEMI, do qual extraímos as questões básicas para nossos objetivos. Depois focalizamos as "propostas de ações" de cada escola, documento de adesão ao programa, ${ }^{4}$
3 Reelaboração, tradução,

ressignificação, como operados aqui, são sinônimos para expressar os usos diferenciados que cada realidade escolar (contexto ou cultura) constrói a partir de uma ideia geral de qualidade.
4 Apesar de o Documento Norteador do ProEMI e as propostas de ações das escolas terem sido amplamente pesquisados, não foi possível trazer muitos elementos especificamente dele neste artigo, evitando fugir do foco e estender demais o texto. 
e os sítios de cada instituição na internet, já que eles trazem boas informações sobre as atividades realizadas e possibilitam perceber a concepção de vários segmentos da escola sobre a eficácia e os interesses das ações desenvolvidas. As entrevistas, porém, foram nosso principal instrumento de pesquisa, contribuindo para complementar, adensar, incrementar e problematizar as informações que compilamos nos documentos. Com as entrevistas, buscamos perceber os sentidos de qualidade em cada realidade escolar.

De cada escola, entrevistamos dois professores e um membro do núcleo gestor, totalizando seis depoimentos. Escolhemos como depoentes docentes que estavam na escola durante o período de nosso estudo, não importando a função desenvolvida em todos os 20 anos, pois, como há alta rotatividade de funções dentro da escola e de docentes entre as escolas (SANTOS, 2007), o fato de o professor permanecer na mesma instituição viabiliza a contribuição para esta investigação. Embora a entrevista tenha sido agendada e combinada com os docentes, apresentando os aspectos relevantes da investigação, evitamos perguntas diretas, com o intuito de estabelecer um diálogo mais informal e criar uma relação de confiança que propiciasse respostas mais seguras para as indagações. Centramos a conversa, então, em questões gerais. Desse modo, não fizemos uma entrevista fechada, nem mesmo uma entrevista semiestruturada nos moldes das perspectivas metodológicas de Richardson (2009) ou Minayo (2010). Optamos pela entrevista dialogada, bastante difundida pelos estudos etnográficos (CLIFFORD, 1998), em que entrevistado e entrevistador discutem situações que envolvem o cotidiano da escola. No desenrolar dessa conversa, direcionamos as indagações para encontrar os elementos que desejávamos para a pesquisa. A conversa, portanto, girou em torno da seguinte questão geral: "como a escola constrói a relação entre o Programa Ensino Médio Inovador e a educação de qualidade?”.

\section{SITUANDO A PESQUISA}

A partir de meados dos anos 1990, pudemos verificar um processo de expansão do ensino médio, que, pela primeira vez na 
história do Brasil, atenderia a uma parcela considerável da população jovem. Com décadas de atraso, se compararmos a realidade brasileira com a de alguns países europeus e com os Estados Unidos, referenciadas pela LDB, Lei n. 9.394/1996, várias inciativas governamentais foram anunciadas, apontando que a educação secundária tomaria novos rumos, seria revolucionada e faria, cada vez mais, parte da vida de jovens e adolescentes. As propostas para o ensino médio, como ações dos órgãos governamentais - nesta pesquisa representadas pelo MEC -, traçavam, juntamente com seus objetivos de formação, um discurso sobre a qualidade na educação, tendo como referências aspectos flutuantes entre a atenção às avaliações internas e externas e ao atendimento a seus objetivos formativos. Assim, alguma ideia de qualidade sempre fez parte das bandeiras políticas que justificavam as intervenções no ensino médio. No entanto, os sentidos construídos e a ênfase em um dos aspectos dessa qualidade variam de acordo com os pressupostos defendidos pela reforma e pela disputa política dos significados do conceito de qualidade (LOPES, 2012).

No início da expansão, durante o primeiro governo de Fernando Henrique Cardoso (FHC), o ensino médio foi propagandeado como sendo um ensino para a vida e, além da LDB, tinha como referenciais as Diretrizes Curriculares Nacionais para o Ensino Médio (DCNEM), os Parâmetros Curriculares Nacionais do Ensino Médio (PCNEM) e o Decreto n. 2.208/1997. De forma geral, essa proposta para o ensino médio centrava-se na formação geral, tecnológica e propedêutica, trazendo a ideia de um "novo ensino médio". O foco da reforma era adaptar o ensino às novas determinações do mundo do trabalho centrado nas transformações técnicas e científicas, na revolução tecnológica e na sociedade da informação. Como lema, tratou-se de enunciar que "o ensino médio, agora, é para a vida”, aproximando a sala de aula dos elementos cotidianos da vida do aluno e dos interesses imediatos da sociedade (BRASIL, 1999).

Segundo os documentos do novo ensino médio, junto com o caráter de terminalidade da educação básica, a LDB estabelece um princípio de formação geral, unificando a formação 
tecnológica (e não, especificamente técnica) com a formação humana, vinculação da educação com o mundo do trabalho e a prática social, consolidando a preparação para o exercício da cidadania e propiciando preparação básica para o trabalho (BRASIL, 1999). Vemos a qualidade associada com a cidadania e a formação para o trabalho perdurando durante os oitos anos do governo FHC. Avaliar a qualidade, então, é também verificar os índices de empregabilidade, percebendo se a educação "cumpre" sua função de proporcionar melhores condições de emprego e renda aos jovens brasileiros (SANTOS, 2007). Concomitante a esse pensamento, foi igualmente forte o apelo referendando a qualidade com as avaliações de desempenho em exames nacionais e internacionais e os índices gerais de aprovação, reprovação e abandono escolar copilados pelo Censo Escolar. A análise desses referenciais mantinha decisiva influência no discurso de qualidade, ou não, da educação (FREITAS, 2004).

Já durante os dois mandatos presidenciais de Luís Inácio Lula da Silva, o ensino médio ganhou uma proposta integrada. Apesar de nos primeiros anos apenas administrar a herança de FHC, o governo Lula mostrou-se sensível ao apelo de uma parcela significativa dos educadores, muitos da base de apoio político do Partido dos Trabalhadores (PT), e revogou o Decreto n. 2.208/1997. Agora a lei sinalizava para o ensino médio integrado, de acordo com o Decreto n. 5.154/2004. Com isso, uma reviravolta dessa política começava a ser esboçada no primeiro mandato do presidente Lula. O MEC propôs uma guinada na relação entre a formação técnica e o ensino médio ao apresentar uma proposta de ensino médio integrado ao profissionalizante, pensando a articulação da formação profissional com o próprio ensino médio. Assim, o Decreto n. 2.208/1997, que reforçava a visão dual na formulação e na condução das políticas de educação básica e da educação profissional e tecnológica do MEC, perdeu seu efeito legal. O Decreto n. 5.154/2004 foi, desse modo, um marco importante na medida em que revogou a norma que delimitava a separação entre o ensino médio e a educação profissional técnica de nível médio e delegou as formas de articulação entre a educação profissional (integrada, concomitante 
e subsequente) e o ensino médio para a decisão das redes e instituições escolares. Nas palavras de Maria Helena Lodi, diretora do Departamento de Políticas do Ensino Médio do MEC, a oferta do ensino médio integrado contribuirá para a:

[...] melhoria da qualidade dessa etapa final da educação básica. Em termos curriculares, essa modalidade reunirá conteúdos do Ensino Médio e da formação profissional que deverão ser trabalhados de forma integrada durante todo o curso, assegurando o imprescindível diálogo entre teoria e prática. Aos alunos será dada a oportunidade de concluir o Ensino Médio e, ao mesmo tempo, adquirir uma formação específica para sua inclusão no mundo do trabalho. O Ensino Médio integrado proporcionará melhores condições de cidadania, de trabalho e de inclusão social aos jovens e adultos em busca de uma formação profissional de qualidade e de novos horizontes para suas vidas. (BRASIL, 2006, p. 4)

A integração do ensino médio passou a ser referência, medindo a qualidade por uma suposta relação entre teoria e prática. A possibilidade de incluir o jovem egresso no mundo do trabalho e da formação cidadã, além de se tornar um objetivo, passou a ser marca para avaliar a qualidade de educação. Inicialmente, não sabemos como seria possível monitorar os níveis de formação cidadã e de usos do conhecimento adquirido para a incorporação no mundo do trabalho pelos alunos egressos do ensino médio, a ponto de serem expressão da avaliação. Talvez, numa perspectiva pragmática de "desenvolvimento social”, retomando as máximas do reflexo deweyano entre sociedade e educação, fosse possível entender a relação entre teoria e prática anunciada na fala de Lodi. Depois, parece clara a determinação de entender a qualidade como resultado das avaliações gerais, relacionando-a com aspectos que possibilitam a empregabilidade ou o acesso ao nível superior.

De fato, as avaliações gerais permaneceram, assim como o monitoramento dos índices pelo Censo Escolar, mas agora reforçado pela crescente preocupação com os resultados do Exame Nacional do Ensino Médio (Enem), mecanismo que 
conjuga tentativas de avaliar a qualidade da educação com o sistema de acesso ao ensino superior. Desse modo, a avaliação da qualidade convive com os fins da proposta para o ensino médio - formação cidadã e inclusão no mundo do trabalho - e com avaliações de desempenho em âmbito nacional.

No final do segundo governo Lula e no início da presidência de Dilma Rousseff, começou a tomar forma a atual proposta do MEC. O Programa Ensino Médio Inovador (ProEMI) pretende induzir o redesenho dos currículos do ensino médio, compreendendo que as ações

[...] propostas inicialmente vão sendo incorporadas ao currículo, ampliando o tempo na escola e a diversidade de práticas pedagógicas, atendendo às necessidades e expectativas dos estudantes do ensino médio. (BRASIL, 2013, p. 9)

Segundo o documento, o objetivo do redesenho curricular é garantir o acesso à educação de qualidade, atendendo "às necessidades e expectativas dos jovens brasileiros", dado que, para atingir tal escopo, é necessário compreender os sujeitos e as juventudes presentes no ensino médio brasileiro e seus direitos à aprendizagem e ao desenvolvimento integral.

As fontes de informação para a elaboração do ensino médio inovador foram o Censo Escolar 2011, realizado pelo Instituto Nacional de Estudos e Pesquisas Educacionais Anísio Teixeira (Inep), órgão ligado ao MEC, e a Pesquisa Nacional por Amostra de Domicílios (Pnad) 2009 e 2011, conduzida pelo Instituto Brasileiro de Geografia e Estatística (IBGE). Como apresentado no documento:

Em relação às taxas de aprovação, reprovação e abandono escolar, os índices apresentados no Censo Escolar 2011 estão longe do desejável. A taxa total de aprovação na 1ª. Série do Ensino Médio foi de 70\%, enquanto 18\% reprovaram e 11\% abandonaram a escola nesse ano. (BRASIL, 2013, p. 11)

Diante deste cenário observa-se a necessidade de ampliação e fortalecimento de políticas efetivas que garantam o direito ao ensino médio de qualidade para todos e as condições necessárias, por meio da ampliação da 
Desse modo, o ProEMI mantém a histórica preocupação com os indicadores da educação, sempre que possível fazendo relação com o desempenho - aprovação, reprovação, evasão, distorção idade-série, percentual de alunos matriculados, resultado do Enem, resultado do Índice de Desenvolvimento da Educação Básica (Ideb), resultado do Programa Internacional de Avaliação de Estudantes (Pisa) -, buscando atender aos quesitos quantitativos da avaliação. Porém, deixa subentendido o conceito de qualidade, subsumindo o objetivo às "necessidades e expectativas" dos alunos do ensino médio. Diferentemente de outros momentos, quando a "preparação para o trabalho", a "formação cidadã", a "inclusão na era digital" ou a "incorporação ao mundo produtivo" tinham assento nos fins da educação, as "necessidades e expectativas" abrem ainda mais possibilidade de construir diferentes parâmetros para dialogar com a ideia de qualidade na educação.

Compreendemos que as propostas curriculares para o ensino médio, nos últimos 20 anos, tiveram conotações diferentes, apesar da insistência na medição quantitativa dos resultados por meio de avaliações gerais. Para efeito de estudo, dividimos o período em três fases: a primeira corresponde aos dois mandatos de FHC (1991-2002), com a proposta de um "ensino médio para a vida"; a segunda envolve os oito anos de governo de Luís Inácio Lula da Silva (2003-2010), conhecido pela proposta de um "ensino médio integrado"; já o terceiro momento está relacionado à ascensão de Dilma Rousseff ao poder central (2011-2014) e tem como norte o projeto de um "ensino médio inovador". Admitimos que a divisão posta aqui pode ser considerada, até certo ponto, inconsistente, já que as propostas não nascem da vontade individual de um legislador ou de um dirigente, nem mesmo em um determinado ciclo de tempo (LOPES, 2006). Assim, pensar em data de nascimento e em paternidade das propostas curriculares não cabe em nosso trabalho. No entanto, reafirmamos a necessidade de determinar os três períodos, 
objetivando melhor entender o panorama da construção da ideia de qualidade que nos interessa investigar, mas também alertando para a flexibilidade de construção dos objetos estudados, tanto no que diz respeito aos formuladores das propostas, quanto ao tempo ou governo em que elas foram operando.

Tomando tais cuidados, podemos resumir os elementos de cada proposta. O "ensino médio para a vida" trazia a ideia de avaliação da qualidade, dentro do jogo discursivo do governo neoliberal de FHC, centrado em três elementoschave: formação para o trabalho, formação para a cidadania e formação para a inclusão às novas tecnologias. No "ensino médio integrado", dentro da reação antiliberal, tomando inclusive decisões de romper com várias normas do período passado, a avaliação da qualidade tomava como referência a formação geral, numa ideia de cultura ampla (incluindo desde a inserção no mundo tecnológico até a preparação básica para o mundo produtivo) e a formação cidadã. O "ensino médio inovador" - apesar de toda possibilidade de continuidade do projeto, dadas as condições similares de sua base de apoio e, ainda, por ser continuação declarada de um projeto de poder - apresenta diferenças sensíveis com relação à noção de qualidade. Abandonando a ideia de formação para o trabalho e qualquer noção de formar para a cidadania, o ProEMI traz a lembrança de formação para atender às "necessidades e expectativas" dos alunos do ensino médio. Mesmo que essa máxima, "necessidades e expectativas", seja preenchida em alguns momentos do documento com elementos que lembram a formação geral e, em outros, com elementos que remetem à formação para o mundo do trabalho, a abertura de pensar as necessidades e as expectativas dos alunos pode gerar inúmeras interpretações sobre os fins educacionais.

Ademais, nas últimas duas décadas, esses discursos sobre a qualidade, discursos difusos, sem clareza de sentidos, rondaram a escola de ensino médio. Entendemos que as escolas, com sua dinâmica própria, preencheram os sentidos apontados nos referenciais oficiais a partir de seu contexto, dando um fechamento, mesmo que provisório, ao que desejavam construir como fins de seu projeto educacional. Isso explica, 
em parte, a continuidade de alguns traços básicos da qualidade (formação para o trabalho e para a cidadania em propostas antagônicas, por exemplo), forjada pela lógica da escola. O que investigamos, porém, é como a escola se comporta quando os referenciais ficam cada vez mais abertos, incluindo necessidades e expectativas, num processo que abarca continuidades e rupturas (e não simplesmente do ponto de vista da política partidária). Enfim, como a escola lida com a abertura dos fins da educação para as necessidades e as expectativas, num contexto que envolve fortemente a formação para o trabalho e para a cidadania e ainda precisa responder às avaliações quantitativas de âmbito nacional como o Enem e o Ideb.

\section{POLÍTICA COMO CONSTRUÇÃO EM DIFERENTES CICLOS}

Queremos entender como os docentes percebem, contextualmente, a qualidade da educação, tomando como referências as atividades realizadas na escola, desde as ressignificações das políticas para o ensino médio inovador. Entendemos, com Ball (1994a, 1994b, 1998), Mainardes (2006) e Lopes (2006), que investigar as ressignificações das políticas na escola é examinar conexões, relações, apropriações, traduções e interdependências, vislumbrando que políticas são processos construídos contextualmente. Desse modo, as práticas políticas são específicas e contextualizadas, sendo efetivadas de maneira diversificada de acordo com a dinâmica de cada escola. Pensando assim, atores envolvidos na (re)elaboração das políticas, como professores, gestores, dirigentes e técnicos das secretarias e do MEC, influenciam os rumos e a dinâmica de cada ação. Além disso, a situação da escola, seu reconhecimento, sua posição na comunidade e seu poder de enfrentamento e de mediação na relação com os órgãos - que pode ser resultado de vários processos históricos e sociais, algo que Ball resumiu, para facilitar a compreensão, como a cultura escolar - são também fatores a serem considerados no entendimento de como as políticas são mediadas.

Com a perspectiva acima, estamos logo nos afastando de concepções que pensam a política como factível de 
implementação na escola, após ser formulada em alguma instância estatal. Sem desconsiderar o papel do Estado na elaboração de políticas, reconhecendo inclusive sua força de indução de práticas nas escolas, consideramos que várias circunstâncias corroboram as políticas educacionais. Desse modo, cremos que as propostas estatais são construídas, elaboradas, reelaboradas em várias circunstâncias na prática docente, ressignificadas contextualmente pelos sujeitos que atuam na escola com base em seus saberes/poderes, nas várias compreensões e na apropriação do mundo. Por ressignificação entendemos os próprios sentidos construídos e reconstruídos na/pela escola numa relação de compreensão e tradução das propostas, configurados em projetos híbridos (BALL, 1994a), e não os novos sentidos que professores e gestores poderiam atribuir a partir de um sentido original da política. Para nós, o hibridismo consiste na "mistura de lógicas globais, locais e distantes, sempre recontextualizadas" na prática docente, influenciados pelo contexto escolar (LOPES, 2005, p. 56).

A ressignificação, portanto, não acontece simplesmente pela ação de seus intérpretes (professores e gestores) na escola. Como mostra Ball (1998), não se trata de colocar políticas em prática, pois este é um processo criativo, sofisticado e complexo que também se localiza sempre em um determinado contexto e lugar. Falar de contexto, pela força do uso desse termo nas perspectivas estruturalistas (principalmente nos usos do termo pela esquerda marxista althusseriana), remete à ideia de relação direta com os aparelhos ideológicos, com a base econômica e política e, em maior grau, com uma arrebatadora força da história e da cultura. Contrariamente, definimos contexto como os movimentos realizados pela escola, (re)construindo sentidos globais e locais, em várias direções e, principalmente, em relação aos órgãos governamentais, à comunidade escolar e à própria escola. É nessa perspectiva que focalizamos, de forma geral, os sentidos consolidados na escola para a qualidade da educação, que de alguma maneira perpassa as ações desenvolvidas pelos docentes, e as relações de ressignificação e tradução possíveis com o documento do ProEMI. 
Para realizar essa interpretação, utilizamos a concepção do "ciclo contínuo de políticas" de Stephen Ball e Richard Bowe (1998), como apresentado e discutido por Lopes (2006), Lopes e Macedo (2006, 2011), Ball e Mainardes (2011) e Mainardes (2006). Nessa concepção, as políticas educacionais não são, de forma estanque, oriundas dos governos e da estrutura estatal, mas fazem parte de vários contextos: o contexto de influência, o de produção de textos e o da prática. Assim, tentamos nos afastar das análises estadocêntricas que consideram a política como direcionada pelo Estado e implementada pela escola, deixando quase nenhuma possibilidade de reelaboração pelos sujeitos, a não ser resistir ou executar o projeto imposto.

Com a abordagem do "ciclo contínuo de políticas", Ball (1998, 2011) e Ball e Bowe (1998) destacam a complexidade inerente à análise da política educacional,

[...] enfatizando os processos micropolíticos e a ação dos profissionais que lidam com as políticas no nível local e indica a necessidade de se articularem os processos macro e micro na análise de políticas educacionais. (MAINARDES, 2006, p. 48)

O ciclo contínuo de Stephen Ball e Richard Bowe é constituído, inicialmente, pelos contextos: de influência, da produção de textos e da prática. Posteriormente, dois outros momentos são apresentados: o contexto dos resultados (efeitos) e o da estratégia política. Todos, cabe ressaltar, estão inter-relacionados, sem nenhuma dimensão linear ou sequencial obrigatória entre eles.

Embora alguns autores, como Chagas (2010, p. 27), apontem que no primeiro contexto

[...] as políticas começam a ser planejadas e influenciadas pelas mais diversas reivindicações de diferentes grupos da sociedade e pelos conceitos significativos que estão presentes nos discursos desses grupos,

concordamos com Lopes (2006), quem assinala que não faz sentido a ideia de as políticas serem determinadas no contexto de influência, ao custo de inviabilizar a própria 
teoria complexa do ciclo. Isto é, a política não nasce, necessariamente, no contexto de influência e é ressignificada somente no contexto da prática. Por sua caracterização cíclica, as influências são constantes, denotando a complexidade da elaboração, da significação e da ressignificação das políticas educacionais.

De maneira didática, entretanto, podemos afirmar que é no contexto de influência que as políticas públicas são também significadas e os discursos políticos são construídos de forma mais sistemática.

É nesse contexto que grupos de interesse disputam para
influenciar a definição das finalidades sociais da educação
e do que significa ser educado. Atuam nesse contexto
as redes sociais dentro e em torno de partidos políticos,
do governo e do processo legislativo. É também nesse
contexto que os conceitos adquirem legitimidade e
formam um discurso de base para a política. O discurso
em formação algumas vezes recebe apoio e outras vezes
é desafiado por princípios e argumentos mais amplos que
estão exercendo influência nas arenas públicas de ação,
particularmente pelos meios de comunicação social. Além
disso, há um conjunto de arenas públicas mais formais, tais
como comissões e grupos representativos, que podem
ser lugares de articulação de influência. (MAINARDES,
2006, p. 52)

O contexto de influência é, então, caracterizado por disputas na construção dos discursos que definirão os princípios gerais da política educacional. Vários grupos de interesse disputam significações do mundo para influenciar os sentidos das finalidades sociais das políticas de educação. Aqui, os conceitos adquirem legitimidade e formam um discurso de base para a política. Dizer isso, insistimos, é diferente de afirmar que as ideias nascem nesse contexto e são, a partir dele, irradiadas para os outros contextos (mesmo que passando pelos crivos e disputas em cada um deles).

Participam desse contexto agências multilaterais, como o Banco Interamericano de Desenvolvimento (BID), o Fundo Monetário Internacional (FMI), o Banco Mundial (BM), mas 
também associações docentes, sindicatos classistas (dos trabalhadores e dos empresários), organizações não governamentais (ONGs), entidades com diversos interesses públicos, privados, religiosos e classistas. Enfim, grupos de interesse que disputam não somente a direção para as políticas educacionais, mas, e talvez principalmente, a constituição de relações (políticas, sociais, econômicas, culturais) a partir de seus arcabouços de verdades.

No contexto da produção de textos, acontece a caracterização dos textos das políticas educacionais. Envolve, de forma geral, técnicos dos governos, parlamentares, especialistas em diversas áreas, assessores parlamentares, consultores de ONGs e pesquisadores de várias instituições.

Os textos políticos, portanto, representam a política. Essas representações podem tomar várias formas: textos legais oficiais e textos políticos, comentários formais ou informais sobre os textos oficiais, pronunciamentos oficiais, vídeos, etc. Tais textos não são, necessariamente, internamente coerentes e claros, e podem também ser contraditórios. (MAINARDES, 2006, p. 52)

Na produção de textos, os antagonismos, os conflitos apresentados no contexto de influência circulam em disputas por hegemonias para representar e representar-se no texto escrito. Os textos são o resultado de disputas, acordos, encontros, alianças entre grupos que atuam em diferentes lugares, com diferentes concepções, na disputa para controlar as representações da política. Nesse contexto, os textos políticos tomam forma escrita com a pretensão de atender ao interesse público geral.

Finalmente, o contexto da prática pode ser caracterizado pelas ações ocorridas nas escolas, onde são realizadas:

[...] leituras dos textos das políticas e estes são reinterpretados e, assim, são produzidos novos discursos que perpassam os demais contextos, em uma circularidade contínua. Nesse sentido, devemos pensar a prática como parte da política, visto que sentidos da prática estão representados nas políticas de forma bastante imbricada, evidenciando a constante produção de políticas no 
Evidenciando, contingencialmente, que é esse contexto que nos interessa, acreditamos que a escola não pode ser vista apenas como receptáculo de políticas pensadas longe de sua realidade, tendo a função somente de implementar, como vítima indefesa, tudo o que é elaborado alhures. No contexto da prática, a política (enquanto proposta) está sujeita à interpretação e à recriação, produzindo efeitos e consequências que podem representar mudanças e transformações significativas na política oficial. A política, como proposta, ao chegar às escolas, é ressignificada, recontextualizada por hibridismo pelos profissionais da educação que ali atuam. O professor, em sua função docente, tem a liberdade de recriá-la e reinventá-la. A política será "interpretada de diferentes formas, uma vez que experiências, valores e interesses são diversos" (MAINARDES, 2006, p. 53). Como parte do ciclo, os agentes mantêm intensa relação com sua construção, seja na ressignificação das propostas apresentadas e nas releituras e reinterpretações dos textos das políticas, seja nas trocas constantes entre os vários contextos.

Os outros dois contextos propostos por Ball, o da estratégia política e o dos efeitos/resultados, surgem, de acordo com Oliveira e Lopes (2011), da tentativa de possibilitar ao ciclo de políticas mais potência na investigação das conexões que se estabelecem ao longo do movimento das políticas. Oliveira e Lopes (2011, p. 22) consideram que esses contextos foram introduzidos com a intenção de tentar minimizar a dicotomia entre proposta e implementação das políticas e para atender ao "compromisso com uma agenda curricular crítica", deixando clara a preocupação com o "impacto das políticas sobre o quadro social e a necessidade de lidar com as desigualdades causadas e com a urgência de promoção de justiça social". Esses dois últimos contextos, no entanto, comprometem "os três contextos primários como arenas políticas, como lugares e grupos de interesse atravessados por disputas e embates", na 
medida em que podem reforçar a concepção de que o Estado elabora as estratégias para garantir as "finalidades educacionais de sua agenda política e de um contexto a quem compete avaliar seus resultados com relação à implementação dessa agenda" (OLIVEIRA; LOPES, 2011, p. 22).

Ou seja, mantém a ideia de que as políticas têm origem no contexto de influência, capaz da proposição de ações políticas que modifiquem ou mantenham determinadas finalidades, bem como mantém uma relação determinista de avaliação de políticas, conectada à consecução de finalidades na prática. (OLIVEIRA; LOPES, 2011, p. 23)

Nessa perspectiva, o foco da análise de políticas deve incidir sobre a formação do discurso da política e sobre a interpretação ativa que os profissionais que atuam no contexto da prática fazem para relacionar os textos da política à prática. Como defende Mainardes (2006), cada um dos contextos apresentados por Ball e Bowe (1998) são constituídos de arenas, de lugares de discussão, de ambientes de disputas e de grupos de interesses que desejam influenciar as políticas. São, assim, ambientes que envolvem embates pela significação das políticas, certamente relacionando com sua compreensão de mundo e seus interesses no mundo.

\section{QUALIDADE NA EDUCAÇÃO: CONSTRUÇÃO DE SENTIDOS EM VÁRIOS CONTEXTOS}

Com a compreensão de que as escolas são arenas de disputas de diversos projetos, onde convivem atores sociais que pensam e agem no mundo movidos por interesses diversos, nem sempre conscientes, inteligíveis e disciplinados, buscamos perceber os sentidos de qualidade na educação operados nas escolas. Por serem duas escolas que estão desenvolvendo ações com base no ProEMI, proposto pelo MEC, intentamos relacionar as perspectivas de qualidade desse programa e as apresentadas pelos docentes. Queremos construir essa relação sem desconsiderar que outros sentidos de qualidade, muitos deles oriundos de outras propostas oficiais de reformas educacionais, continuam circulando nas escolas, 
5 Os jornais pesquisados foram O Povo (disponível em <www. opovo.com.br>) e Diário do Nordeste (disponível em <www. diariodonordeste.com.br $>$ ) dialogando com os sentidos de qualidade (re)construídos pelos atores escolares. Em suma, pesquisar sobre qualidade na educação exige perceber os híbridos sentidos de qualidade que permeiam o ambiente escolar, ação só possível, em nossa compreensão, contextualizando o espaço escolar.

A seguir apresentaremos as escolas e as falas dos entrevistados, intercalando a discussão e as entrevistas a fim de facilitar nossa argumentação. Como os depoentes solicitaram o anonimato das falas, trataremos a primeira escola pelo codinome de Capital e, por sua vez, a segunda escola pelo codinome de Urbana. Ressaltamos ainda que os entrevistados 1 , 2 e 3 atuam na escola Capital e os entrevistados 4, 5 e 6 são depoentes da escola Urbana.

A primeira escola pesquisada, Capital, é reconhecida como uma das melhores escolas públicas do estado do Ceará, está situada em um bairro central da cidade, recebendo alunos de vários bairros periféricos e da região metropolitana de Fortaleza. Tal reconhecimento pode ser percebido na intensiva divulgação de suas atividades em vários meios de comunicação, principalmente nos jornais impressos de grande circulação e nas redes sociais (Facebook e Twitter), além do sítio da escola na internet. Segundo o membro do núcleo gestor, a escola se esforça para manter o reconhecimento de seu desempenho e, por conseguinte, atrai a atenção das autoridades do Estado e dos meios de comunicação. A escola é manchete, segundo ele, em virtude das filas que se formam durante as matrículas, já que a procura é bem maior do que a disponibilidade de vagas. ${ }^{5}$ Também está presente nas matérias sobre o desempenho dos alunos das escolas públicas no Enem e na aprovação em outros processos de acesso ao ensino superior. Porém, o entrevistado faz questão de frisar que a escola não faz propaganda, apenas repassa as informações para os veículos de comunicação:

Não há grande preocupação em buscar inserir informações nos jornais. Eles é que sempre nos procuram para pedir entrevistas, para saber informações sobre nossos alunos, sobre o [desempenho da escola no] Enem, sobre as filas de matrículas no início de cada ano. É, ao contrário, a fama da escola que traz muita procura da mídia. Claro que isso gera também mais popularidade, 
mais fama, mais procura, porque afinal quem não quer ver seu filho estudando numa boa escola pública? (Entrevistado 2)

A escola Urbana, por sua vez, está localizada em uma cidade de médio porte no interior do Ceará, tendo sido a primeira escola de ensino médio da região e, por isso, principal polo educacional das cidades circunvizinhas. Atualmente, porém, disputa alunos e atenção com outras duas escolas de ensino médio na mesma cidade. Com uma estrutura física para 1200 alunos, vem sofrendo com a diminuição gradativa da procura. A maior parte de seu quadro docente é de professores temporários, ${ }^{6}$ com carência maior ainda nas áreas de matemática, física e língua estrangeira. Alguns relatos dão conta de que em vários anos não foi possível completar todas as aulas dessas disciplinas, sendo resolvido o problema com atividades complementares e outros arranjos feitos pela escola para não prejudicar os alunos. ${ }^{7}$ Segundo o gestor da escola, a conquista do ProEMI se deu pela mobilização da comunidade escolar e pelo reconhecimento histórico do papel da escola na formação de várias gerações:

A partir da ideia, que veio da Crede, ${ }^{8}$ mobilizamos a comunidade, fizemos reuniões, aprovamos um plano de ação e ficamos na expectativa de sermos escolhida. Sabíamos que só poderia ser uma escola nesse município. A nossa é a mais antiga, a mais reconhecida, a mais tradicional. Tinha que ser a nossa. A nossa história fez a diferença na hora da decisão. (Entrevistado 4)

Podemos considerar essa descrição da escola Urbana como ativista, já que defende o legado histórico, viabilizando sua necessidade pelos serviços prestados ao longo dos anos e gerações. Ainda assim, ela precisa assegurar sua existência, reafirmando sua história, disputando espaços e mostrando a importância de suas ações para a cidade e para a região de que faz parte.

O reconhecimento da escola Capital, entretanto, acontece de maneira mais direta, sendo considerado "natural", fruto do desempenho apresentado pela instituição. Nas palavras do Entrevistado 1:
6 A contratação de professores temporários no Ceará tem se caracterizado como um dos grandes problemas da educação. Além da falta de estabilidade e da impossibilidade de construção da carreira docente, o trabalho precário dificulta pensar a continuidade das ações na escola. Segundo o site da Secretaria da Educação do Ceará (Seduc), o estado possui 13 mil professores efetivos, distribuídos nas funções de docentes, suporte pedagógico, técnico e núcleo gestor escolar; além de 11 mil temporários, o que representa $45 \%$ da rede. Outra questão: o salário inicial de um professor concursado da rede estadual é de $\mathrm{R} \$ 2.444,00$, ao passo que o temporário recebe apenas $\mathrm{R} \$ 1.773,00$. Informações disponíveis em: <www.seduc.ce.gov.br>, acesso em: 19 jul. 2014.

7 Nesta pesquisa, vários professores admitiram utilizar tarefas e trabalhos para casa a fim de substituir aulas que não foram ministradas. Santos (2007) também aponta essa realidade em trabalho sobre a semestralidade no interior cearense.

8 A Seduc está dividida em 20
coordenadorias regionais de
educação, denominadas Crede. 
Não temos preocupação direta com a divulgação de nossos resultados. Temos preocupação em manter e ampliar as conquistas. São as conquistas que atraem mais interesse pela escola. [...] Os resultados geram uma [boa] repercussão na mídia; não é a mídia que traz os resultados. Nós temos fama por causa dos resultados. Os resultados é que trazem a fama.

Em uma busca rápida nas páginas dos dois principais jornais impressos do estado, conseguimos localizar dezenas de matérias sobre a escola. Os assuntos mais recorrentes são, de fato, os temas apresentados pelo gestor da escola (Entrevistado 2). Porém, vários outros tópicos, como cursos de educação integrada, olimpíadas escolares, feira de ciências, participação da escola em eventos nacionais, reconhecimento recebido pelos professores e também pelos gestores, prêmios conquistados pelos alunos em concursos nacionais de matemática, de química e de história e outras premiações dos discentes (inclusive em disputas esportivas), estão entre as manchetes dos diários cearenses. $\mathrm{O}$ reconhecimento da escola, a ideia de ser referência é, assim, uma marca que professores e gestores fazem questão de exaltar. É com esse reconhecimento que a escola constrói os sentidos sobre si. Nas palavras do Entrevistado 2:

[...] sim, a fama é de todos nós. Por isso que é mais fácil lidar com as imposições, com as perseguições. Como somos uma escola diferente, reconhecidamente sindicalizada, qualquer deslize sofremos as consequências. Mas como mantemos o compromisso com a realização das atividades, como damos a resposta pedagógica que o Estado quer, ninguém mexe. Nossa resposta é a qualidade em tudo que a gente faz. Pode perguntar a qualquer um aqui dentro. A qualidade é nosso principal objetivo.

A fama construída pela intensa propaganda e pelos resultados obtidos em vários processos seletivos permite à escola e, por conseguinte, aos professores e gestores voz ativa perante os órgãos administradores. O sentido de empoderamento é visível em várias partes da entrevista. A escola se sente apta a negociar com os órgãos oficiais as condições para sua participação em determinadas propostas políticas. 
A aceitação ou não de uma proposta é, desse modo, questão menor, pois se entende que a escola tem autonomia, conquistada pela reconhecida eficiência de suas ações.

Para a escola Urbana, a proposta do ProEMI foi considerada uma vitória, haja vista as possibilidades de recursos oriundos do governo federal, via MEC, que estavam sendo prometidos para o desenvolvimento das atividades. Diferentemente da primeira escola, esta teve de se mobilizar, fazer pressão, apresentando seus melhores argumentos, para receber o "convite":

Os recursos eram bons. A proposta era excelente. Tínhamos que conseguir nosso espaço. Se a proposta veio para melhorar a qualidade do ensino médio, como a escola que foi pioneira no ensino médio iria ficar de fora? Não podia, podia? Não podíamos ficar de fora, enfrentamos o desafio e fomos escolhidos. Nada contra os outros, mas tradição também é importante. Podemos até hoje estarmos passando por alguns problemas, mas sempre demos nossa contribuição para o município, para o estado. (Entrevistado 4)

A medida da qualidade como um dos elementos tradicionais é marcante na fala do Entrevistado 4. Segundo ele, não se pode pensar em qualidade da educação negando o passado, negando a história da cidade e a contribuição da escola para a formação de muitos líderes municipais de várias épocas. A tradição é, então, elemento definidor na fala do gestor, servindo como âncora para fortalecer e justificar as pretensões da escola.

A escola Capital e a escola Urbana, cada uma com suas armas, construídas de acordo com seu contexto, com as condições existentes, com as diversas disputas que foram consolidando suas culturas, tomam posição no quadro geral da política educacional, influenciando e sendo influenciadas pelos movimentos, enfrentando os desafios da qualidade como um dos elementos de fortalecimento de seus sentidos de si. Como discutem Ball e Bowe (1992), os atores escolares tomam posições em relação às políticas e aos interesses de órgãos da administração escolar de acordo com o (auto) reconhecimento de suas possibilidades. Assim, admitindo o 
conflito, as disputas entre os projetos a serem postos em prática, para ficar com uma expressão utilizada por Ball, Maguire e Braun (2012), há clareza de que o fortalecimento do nome da escola perante a comunidade, mantendo sua fama de instituição de qualidade, permite muitos enfrentamentos que, em outros casos, não seriam possíveis.

Caminhar, contudo, com as ideias de fortalecimento da escola, atendendo aos interesses da comunidade, oferecendo o que os alunos desejam, exige algumas conformações dos discursos dos depoentes. Um docente da escola Capital indica a contradição:

Qualidade é mais do que somente aprovar quase 200 alunos nos vestibulares da cidade, apesar de não ser possível abrir mão disso, pela exigência da própria comunidade escolar. Qualidade é formar para a vida, pra ser cidadão crítico, como disse Paulo Freire, e não apenas aceitar tudo que vem de cima. Nesses dois pontos, nossa escola está de parabéns. Cumpre com sobra o propósito da educação. Por isso, não deixamos ninguém mexer com a gente. Nós decidimos o que é melhor, como fazer. Com muita democracia, com muita participação. (Entrevistado 3)

Desse modo, mesmo reconhecendo que existe problema em aceitar alguns referenciais de qualidade pedidos pelas políticas, a escola segue algumas diretrizes quantitativas, atendendo aos interesses comuns da política posta e da sociedade, pois entende que faz parte de como o mundo se realiza. É visível, assim, o conflito entre uma perspectiva focada nos resultados, nas aprovações e o desejo de formação mais geral, cuidando de aspectos que possibilitem a formação humanística na perspectiva de formação cidadã.

Essa mesma ideia de formar para a cidadania está no discurso do gestor. Ele une duas preocupações básicas, também já reveladas em outras vozes da escola: manter a autonomia da escola e desenvolver uma educação de qualidade que fuja do padrão quantitativo.

De nada adianta formar somente com conteúdos. 0 aluno precisa saber pensar, caminhar com suas próprias pernas, refletir sobre o mundo que vive e lutar para mudar. Passar no vestibular, ser reconhecido como uma escola que aprova muito é super importante. 
Mas não é o fim da educação. Precisa investir na formação humana, na construção de consciências que possam exigir seus direitos. Escola de qualidade precisa unir os dois objetivos num só. Só assim somos respeitados. Só assim mantemos nossa autonomia, enfrentamos os autoritarismos do governo da Seduc, desse povo que não sabe o que é uma sala de aula e vive exportando metodologias inovadoras, querendo que a gente imite o que deu certo "num sei onde". (Entrevistado 2)

De fato, na página da escola na internet é possível encontrar várias ações que propõem o "desenvolvimento de habilidades gerais dos alunos", como apresentou o Entrevistado 1. Atividades de estudo sobre meio ambiente, inclusão e diversidade, educação sexual e consciência negra são destaques apresentados pela escola. Entretanto, a chamada central da página é para os dados quantitativos de aprovação, via vestibular, ${ }^{9}$ Enem e Programa Universidade para Todos (Prouni). Tanto pelas falas quanto pela representação no site, a qualidade passa pela quantificação, pelos resultados obtidos nos números de aprovação. A aparente contradição é a forma encontrada pela escola para construir seu sentido de qualidade respondendo às exigências de seu público, mas ao mesmo tempo buscando fortalecer um discurso de superação do tecnicismo.

Todavia, o diretor alerta ainda para as políticas que são inventadas e enviadas para a escola, admitindo que várias propostas convivem, disputam espaços e sentidos, são ativas no desenrolar das atividades docentes. Desse modo, vemos como várias significações, muitas antagônicas, disputam seu lugar dentro do espaço escolar.

Para a escola Urbana, o raciocínio da qualidade como aprovação não encontra justificativa direta em suas atuações. Os depoimentos apelam para outras significações do que pode ser qualidade:

Sei que há uma febre pelos resultados do Enem. As escolas, principalmente as particulares, fazem questão de colocar placas mostrando seu desempenho, contando os alunos que passaram [...]. Mas eu duvido eles obterem aquele desempenho a partir dos alunos que nós temos, com as condições que nós temos. Nem tudo pode ser medido pelos resultados dos vestibulares, pelas
9 Embora as universidades federais usem o Enem para selecionar os estudantes, a Universidade Estadual do Ceará (UECE) continua utilizando o sistema vestibular. 
aprovações [...], como muitos desejam. Qualidade pra mim não pode ser medida assim. Precisa ver que nem todo mundo pode pagar escola cara. As familias não podem mandar os filhos para estudar fora [em Fortaleza]. Precisam dessa escola, com tudo que fazemos, com nossa história, fruto da vontade e de sonhos [...] de muita gente. (Entrevistado 5)

Qualidade na educação, portanto, representa a possibilidade de existir numa realidade adversa para atender a uma parcela da população que não pode (ou não quer) se deslocar para longe, para outra cidade. A medida é a medida do possível, justificando os números insatisfatórios nas provas de desempenho e, ainda, por meio da alusão à realidade local. Os entrevistados nessa escola insistem em fazer referência aos tempos áureos, quando a escola era reconhecida pela grande contribuição para a cidade e para a região em que está localizada. Tempo em que ter cursado o ensino médio - principalmente, se fosse um curso técnico, de contabilidade ou pedagógico - era essencial ou, nas palavras do Entrevistado 2, "suficiente para trabalhar, para assumir os empregos na prefeitura e nas escolas que precisam de professoras formadas". O ensino médio, então, "fazia sentido, pois bastava ter o diploma para o sujeito ser reconhecido, trazendo reconhecimento também para a escola" e para os professores que atuavam nela, sem o risco, "sem as ameaças de fechar a escola, de mandarem a gente trabalhar em outra cidade, longe daqui”. Defender a escola e a qualidade do ensino a partir da realidade, assim, uma condição de existência da escola, de seu local de trabalho, de suas memórias e, não menos importante, da tradição, contribuindo para o desenvolvimento do lugar. São interesses legítimos de pertencimento, nos quais a memória é um fenômeno social (HALBWACHS, 1990). Com essa máxima de um pertencimento e de um reconhecimento histórico, a tradição é o que mantém a escola viva:

[...] e sempre muda. Muda o governo, muda a proposta. E muda o que querem que façamos como qualidade. Qualidade para o trabalho, para a vida, para o Enem. Como se a escola fosse somente uma máquina de produzir esses tipos de qualidade. Penso que qualidade é a possivel, é a que a gente faz com o aluno que a 
gente tem, com a realidade que a gente tem. Se não tem trabatho para todo mundo, se não tem vaga para todo mundo, como podemos medir nossa qualidade a partir desses parâmetros? Não abrimos mão de aprovar no vestibular, vários passam e nos orgulhamos muito. Mas não ficamos fazendo outdoors e divulgando como proeza da escola. A proeza é do aluno que estudou. A escola só ajuda. (Entrevistado 6)

Tanto quanto a escola Capital, a escola Urbana apresenta suas contradições. A formação de qualidade para o público existente traz o dilema da busca pela aprovação no vestibular, via Enem, e pela inclusão no mundo do trabalho, via empregos precários. Os sentidos que a escola atribui à qualidade são referendados no aluno, como exige o ProEMI, mas apresentados como uma desculpa, uma falta, e não como a afirmação de a escola estar cumprindo sua função. O olhar condenatório para a outra realidade, a realidade da outra escola que aprova, pode induzir o sentimento de vontade de aproximação com aquela realidade. Quer dizer: não há convicção em seu trabalho; em sua definição de qualidade. Há o sentimento de falta, revestido de "possível”. E quando o "impossível” acontece? É tomado como exceções, como deslocamento da qualidade: sai da escola, passa para o aluno. Nos casos de aprovação, a proeza passa a ser do aluno, não da escola.

O fato de a proeza ser atribuída ao aluno não faz sentido para a escola Capital. Sem ceder ao cálculo para medir sua qualidade, apontando a necessidade de unir a formação geral à formação técnica, de se preocupar com a consciência dos indivíduos e com a "soma de conhecimentos para os alunos enfrentarem a vida lá fora” (Entrevistado 2), o depoimento abaixo consolida a visão da escola sobre a qualidade:

Qualidade é tudo que fazemos em prol de nosso aluno. Aula de qualidade é aula que o aluno aprende. Por isso que o projeto na escola dá certo. Não porque a Seduc exige; não porque está no documento do [ensino médio] inovador. Funciona porque buscamos adaptar à realidade do nosso aluno. Temos essa flexibilidade, dada pelo próprio documento norteador, de adaptar. A técnica [da Seduc] pode até achar ruim, mas mostramos que 
conhecemos o documento, que sabemos o que estamos fazendo, que não começamos ontem. Antes dela, antes do inovador, já fazíamos a qualidade da educação no estado. E esse reconhecimento é geral: todo mundo reconhece nossa escola como boa. (Entrevistado 3)

Desse modo, sabendo de sua força no quadro geral, os depoentes vão expondo os enfrentamentos, as disputas para significação das políticas e do projeto de qualidade que consideram viável. Mais do que hegemonizar um tipo de qualidade, que pelo histórico geral da escola seria pelo desempenho quantitativo de seus alunos, buscam estabelecer um elo com a formação humanística, considerada essencial para uma vida digna. Tentam, desse modo, construir sentidos que caibam dentro dos limites de ação da própria escola. Mesmo discordando, em tese, de uma formação tecnicista, é nela que encontram elementos para se manterem no jogo, nas disputas por significação que viabilizam as políticas. Corroborando as ideias de Ball (1998), são nesses sentidos que as escolas criam suas próprias políticas, aperfeiçoando e fixando aspectos das decisões políticas nacionais dentro de suas próprias culturas e práticas laborais. As escolhas, mais do que resultados de opções realizadas pelos sujeitos nas escolas, são negociações com os diversos movimentos em disputa, desde lutas que envolvem interesses da comunidade escolar e da categoria docente até tentativas de atendimento de diretrizes curriculares, como o documento norteador do ProEMI. Dessa forma, de acordo com Mainardes (2006), podemos perceber a negociação entre os macro e os microinteresses dando formatação a um tipo de política educacional.

Dizer isso significa, segundo nossa leitura de Ball, Maguire e Braun (2012) e de Lopes e Macedo (2006), que vários elementos influenciam a realização da política. Não é possível, portanto, estabelecer um padrão nacional para a qualidade, como também, em nenhuma instância, política nenhuma é implementada. Toda política é construção única da escola, de acordo com seus interesses, condições, disputas, resistências, resultando em produções híbridas. A ressignificação por hibridismo nas políticas de currículo, como apresenta Lopes $(2005,2006)$, em diálogo com Laclau 
(2003) e Tura (2009), faz parte das lutas para consolidar um ideal de qualidade da educação que, por sua vez, passa pela consolidação de um ideal de formação humana. Disputa, então, totalmente interessada, envolvendo os complexos canais e desejos de grupos e indivíduos, alguns revelados, outros impossíveis de se conhecer ou dimensionar.

Entendemos, portanto, que o apego ao passado e aos "tempos gloriosos" funciona para manter a importância da escola Urbana, assim como os números e as aprovações são usados como qualificadores da escola Capital. É na dinâmica do reconhecimento de singularidade que a proposta é "adequada à realidade" (Entrevistado 3) ou "construída de acordo com os interesses e condições dos alunos” (Entrevistado 4), pois não é suficiente "colocar um projeto em tempo integral se a realidade de nosso aluno diz que ele não vem” (Entrevistado 6). A readaptação das atividades do ProEMI, a nosso ver, é a construção da própria política. Não existe política como intenção anterior, como um discurso anterior. A política é construída na escola, mesclando discursos, atribuindo sentidos aos discursos que envolvem os fins da educação e os diversos interesses em disputa na realidade escolar, entendida como muito além do lugar, pois está relacionada contextualmente com o global. É nessas interações que a política se realiza. Com efeito, a proposta (o ProEMI) não é a política, embora não desconsideremos suas possibilidades de influenciar, como leituras, a política a ser realizada. A proposta do ProEMI é um texto e, como todo texto, está sujeita a infinitas leituras e releituras, reinterpretações e ressignificações, construções de sentidos de acordo com contextos. Contextos que, vale repisar, trazem elementos do local e do global, ultrapassando a compreensão imediata das estruturas, pois envolvem embates, lutas, interesses de diversos segmentos em busca da legitimação de suas demandas (LOPES, 2006).

Por fim, reforçamos que o reconhecimento da escola, seja pela comunidade, seja pelos órgãos diretivos do estado, influencia decisivamente a forma como a política será realizada na escola. Contudo, não estamos afirmando que há relação direta entre o nível de reconhecimento e a implementação das políticas na escola. Com efeito, discordamos 
da fórmula de Ball (1998): mais poder igual a menos implementação e, no sentido oposto, menos poder igual a mais implementação. Não acreditamos que exista relação direta entre o grau de poder da escola e a aceitação ou não da política. O que dizemos é muito mais do que isso. Nos dois casos, existem forças e disputas em jogo. E, em qualquer caso, as políticas serão ressignificadas contextualmente e diferentemente em cada realidade.

Dessa maneira, embora seja verdade que a escola Capital tenha alguns trunfos para lidar com os órgãos diretivos, trunfos estes capazes de interferir na forma como tais órgãos pensarão e agirão sobre a escola, o mesmo também ocorre na escola Urbana. Em ambas, as políticas são traduzidas contextualmente.

\section{REFERÊNCIAS}

BALL, Stephen J. La micropolítica de la escuela: hacia una teoría de la organización escolar. Barcelona; Madrid: Paidós Ibérica, 1994a.

Education reform: a critical and post-structural approach. Buckingham: Open University, 1994b.

. Cidadania global, consumo e política educacional. In: SILVA, Luiz Heron da (Org.). A escola cidadã no contexto da globalização. Petrópolis, RJ: Vozes, 1998. p. $121-137$.

Sociologia das políticas educacionais e pesquisa crítico-social: uma revisão pessoal das políticas educacionais e da pesquisa em política educacional. In: BALL, Stephen J.; MAINARDES, Jefferson (Org.). Políticas educacionais: questões e dilemas. São Paulo: Cortez, 2011. p. 21-53.

BALL, Stephen J.; BOWE, Richard. Subject departments and the "implementation" of National Curriculum policy: an overview of the issues. Journal of Curriculum Studies, v. 24, n. 2, p. 97-115, 1992.

. El currículum nacional y su "puesta en práctica”: el papel de los departamentos de materias o asignaturas. Revista de Estudios del Currículum, v. 1, n. 2, p. 105-131, 1998.

BALL, Stephen; MAGUIRE, Meg; BRAUN, Annette. How schools do policy: policy enactments in secondary schools. London: Routlegde, 2012.

BALL, Stephen J.; MAINARDES, Jefferson (Org.). Políticas educacionais: questões e dilemas. São Paulo: Cortez, 2011.

BRASIL. Ministério da Educação. Parâmetros curriculares nacionais do ensino médio. Brasília, DF: MEC, 1999.

Ensino médio integrado à educação profissional. Brasília, DF: MEC, 2006.

Salto para o Futuro. 
. Programa Ensino Médio Inovador: documento orientador. Brasília, DF:

MEC, 2013.

BRASIL. Senado Federal. Lei 9.394, de 20 de dezembro de 1996. Lei de Diretrizes e Bases da Educação Nacional. Brasília, DF: MEC, 1996.

Decreto n. 5.154, de 23 de julho de 2004. Regulamenta o § $2^{\circ}$ do art. 36 e os arts. 39 a 41 da Lei $\mathrm{n}^{\circ} 9.394$, de 20 de dezembro de 1996, que estabelece as diretrizes e bases da educação nacional, e dá outras providências. Brasília, DF: MEC, 2004

Decreto n. 2.208, de 17 de abril de 1997. Regulamenta o parágrafo $2^{\circ}$ do art. 36 e os arts. 39 a 42 da Lei 9.394, de 20 de dezembro de 1996, que estabelece as diretrizes e bases da educação nacional e dá outras providências. Brasília, DF: MEC, 1997.

BUSNARDO, Flávia de Mattos Giovannini. Políticas curriculares para o ensino médio: a atuação da comunidade disciplinar de ensino de Biologia. In: REUNIÃO ANUAL DA ANPEd, 32., Caxambu, 2011.

CANDAU, Vera Maria. Qualidade da educação: um discurso inovador? Rio de Janeiro: Novamerica, 2002.

CANDAU, Vera Maria; LEITE, Miriam S. Diálogos entre diferença e educação. In: CANDAU, Vera Maria (Org.). Educação intercultural e cotidiano escolar. Rio de Janeiro: 7 Letras, 2006. p. 121-139.

CHAGAS, Wagner dos Santos. Do contexto da influência ao contexto da prática: caminhos percorridos para a implementação da Lei 10.639/03 nas escolas municipais de Esteio/RS. São Leopoldo: Unisinos, 2010.

CLIFFORD, James. A experiência etnográfica: antropologia e literatura no século XX. Rio de Janeiro: Editora UFRJ, 1998.

DEMO, Pedro. Qualidade e educação. Campinas, SP: Papirus, 2001.

ENGUITA, Mariano F. O discurso da qualidade e a qualidade do discurso. In: GENTILI, Pablo. Neoliberalismo, qualidade total e educação. Petrópolis, RJ: Vozes, 2001. p. 121-135.

FREITAS, Dirce Nei Teixeira de. Avaliação da educação básica e ação normativa federal. Cadernos de Pesquisa, São Paulo, v. 34, n. 123, p. 663-689, set./dez. 2004.

GENTILI, Pablo. Neoliberalismo, qualidade total e educação. Petrópolis, RJ: Vozes, 2001.

HALBWACHS, Maurice. A memória coletiva. São Paulo: Vértice, 1990.

KULESZA, Wojciech; MEDEIROS, Maria Deusa (Org.). Educação básica: da teoria à metodologia. João Pessoa: Universitária, 2000.

LACLAU, Ernesto. Power and representation. In: POSTER, Mark (Ed.). Politics, theory and contemporary culture. New York: Columbia University, 2003. p. 277-297.

LOPES, Alice Casimiro. Conhecimento escolar: ciência e cotidiano. Rio de Janeiro: EDUERJ, 1999. 
. Política de currículo: recontextualização e hibridismo. Currículo sem Fronteiras, v. 5, n. 2, p. 50-64, jul./dez. 2005.

. Discursos nas políticas de currículo. Currículo sem Fronteiras, v. 6, n. 2, p. 33-52, jul./dez. 2006.

. A qualidade da escola pública: uma questão de currículo? In: OLIVEIRA, Marcos Aurélio et al. (Org.). A qualidade da escola pública no Brasil. Belo Horizonte: Mazza, 2012. p. 34-65.

LOPES, Alice Casimiro; MACEDO, Elizabeth. Políticas de currículo em múltiplos contextos. São Paulo: Cortez, 2006.

. Teorias de currículo. São Paulo: Cortez, 2011.

MACHADO, Nilson José. Qualidade da educação: cinco lembretes e uma lembrança. Estudos Avançados, São Paulo, v. 21, n. 61, p. 277-294, set./dez. 2007.

MAINARDES, Jefferson. Abordagem do ciclo de políticas: uma contribuição para a análise de políticas educacionais. Educação \& Sociedade, Campinas, v. 27 , n. 94, p. 47-69, jan./abr. 2006.

MINAYO, Maria Cecília de S. (Org.). Pesquisa social: teoria, método e criatividade. Petrópolis, RJ: Vozes, 2010.

OLIVEIRA, Ana de; LOPES, Alice Casimiro. A abordagem do ciclo de políticas: uma leitura pela teoria do discurso. Cadernos de Educação, Pelotas, n. 38, p. 19-41, jan./abr. 2011.

RICHARDSON, Roberto. Pesquisa social: métodos e técnicas. São Paulo: Atlas, 2009.

SANTOS, Jean Mac Cole Tavares. De novo ensino médio aos problemas de sempre: entre marasmos, apropriações e resistências escolares. Fortaleza: Edições UFC, 2007.

SANTOS, Jean Mac Cole Tavares; OLIVEIRA, Márcia Betânia de. Políticas curriculares no ensino médio: ressignificações no contexto escolar. Currículo sem Fronteiras, v. 13, n. 3, p. 497-513, set./dez. 2013.

TURA, Maria de Lourdes. A recontextualização por hibridismo na prática pedagógica da disciplina Ciências. Currículo sem Fronteiras, v. 9, n. 2, p. 133-148, jul./dez. 2009.

\author{
JEAN MAC COLE TAVARES SANTOS \\ Professor Adjunto da Universidade do Estado do Rio Grande \\ do Norte (UERN), Mossoró, Rio Grande do Norte, Brasil \\ maccolle@hotmail.com
}


